\title{
SiM
}

\section{The Rangeland Cup}

\section{By Rachel D. Mealor and Brian A. Mealor}

T

he Rangeland Cup team competition is an activity to promote critical thinking and cooperative, collaborative work on current topics or topics of historical importance to rangeland ecology and management. In today's world, much of our work is performed as part of a group. This competition, which is held at the SRM Annual Meeting, is intended to build skills in interpersonal communication and group problem-solving, both of which are highly desired qualities for rangeland professionals. The first competition took place earlier this year at the 60th Annual Meeting in Reno/Sparks, NV.

The task of managing rangelands, though complex in the past, has been compounded by new challenges of the 21st century. As a result, the profession and the Society for Range Management are in a constant state of flux. Debates over name changes, policy statements, membership goals, and the purpose of the Society suggest that a clear vision for the future is needed. Who better to provide this vision than future professionals in the field?

The topic for the 2007 Rangeland Cup competition at the SRM Annual Meeting was as follows:

"Apply the state and transition theoretical framework to describe SRM's current and potential future 'identities' as an organization. Include stable states and transitions between those states, identify forces that drive the SRM over particular thresholds into each state, and describe feedback mechanisms that are needed to maintain each state or to revert the SRM to an alternative state."

Nine teams participated from 6 different institutions. Eight individuals graciously volunteered to judge the competition. The competition generated a great amount of interest and interaction between the students and professionals within the organization. The top 3 posters were 1) "The 'Adaptive Phases' of SRM and the Range Profession" from Utah State University, 2) "Society for Range Management: Drivers of Sustainability" from the University of Wyoming, and 3) "Application of State and Transition Model to SRM" from Chadron State College. To showcase these innovative young professionals' work, posters from the competition are presented on the following pages.

Authors are Graduate Student, Department of Renerwable Resources, University of Wyoming, Laramie, WY 82071, rdmealor@uwyo.edu (Rachel); and Sterwardship Director, The Nature Conservancy in Wyoming, Lander, WY 82520, bmealor@tnc.org (Brian).

(Editor's Note: Eight of the poster papers were submitted for publication and are included in this group.) 